\title{
Acción política y social de los pueblos originarios en favor de la configuración del Estado plurinacional comunitario
}

[Artículos de investigación]

\author{
Julián Cárdenas Arias* \\ Jhon Alexander Idrobo Velasco** \\ Ana María León ${ }^{* * *}$ \\ Israel Arturo Orrego Echeverría ${ }^{* * * *}$
}

Recibido: 2 de octubre de 2021

Aceptado: 3 de marzo de 2021

\footnotetext{
* Grupo de Investigación Interinstitucional Tlamatinime y al semillero de investigación filosófica Symbolum. Correo electrónico: jucaviowoaini@yahoo.com; ORCID: https://orcid.org/0000-0002-0905-7391

** Líder del Grupo de Investigación Interinstitucional Tlamatinime y del Semillero de Investigación Eirene Latinoamérica; integrante del grupo de investigación Estudios Interdisciplinarios de la Sociedad y la Cultura. Correo electrónico: jhonidrobo@usantotomas.edu.co; ORCID: https://orcid.org/0000-0002-2228-0002

*** Miembro del Grupo de Investigación en Psicología, Salud, Administración y Docencia (Gipsad), de la Facultad de Ciencias Sociales, Administrativas y Económicas de la Fundación Universitaria de Ciencias de la Salud. Correo electrónico: anamale082@gmail.com; ORCID: https://orcid.org/0000-0002-7246-3755 **** Docente e investigador de la Facultad de Filosofía y Ciencias Humanas de la Universidad Libre de Colombia y de la Corporación Universitaria Iberoamericana. Magister y doctor (c) en Filosofía, especialista en Educación y Cultura Política, profesional en Filosofía y licenciado en Ciencias Teológicas. Correo electrónico: arturo.orrego@gmail.com; ORCID: https://orcid.org/0000-0002-9286-138X
} 
Citar como:

Cárdenas Arias, J., Idrobo Velasco, J. A., León, A. M. y Orrego Echeverría, I. A. (2021). Acción política y social de los pueblos originarios en favor de la configuración del Estado plurinacional comunitario. Campos en Ciencias Sociales, 9(1). https://doi.org/10.15332/25006681.6918

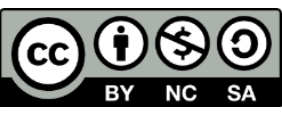

\section{Resumen}

El siguiente documento parte de premisas previas, para demostrar cómo los cambios constitucionales en Bolivia se materializaron a través de acciones sociales y políticas sustentadas en las prácticas y conocimientos ancestrales de los pueblos originarios, dando paso a la construcción del Estado plurinacional comunitario. Así, al abordar el análisis sobre la conformación de Estados plurinacionales en América Latina, se busca evidenciar cambios políticos y epistémicos que experimentan actualmente algunos países en la región. Procesos que son desconocidos por su mínima difusión académica, reduciendo y confundiendo el término plurinacional con otros, como multiculturalismo, pluriculturalismo o multietnicidad, entre muchos más, que desdibujan la postura de esta forma organizativa. En este sentido, aclarar, analizar y entender las apuestas políticas y epistémicas de los Estados plurinacionales permite evidenciar discursos y prácticas propias de países donde la presencia de los movimientos y organizaciones sociales de tipo étnico marcan una multiplicidad de horizontes en diferentes planos, en oposición al condicionamiento de la línea unidimensional de la lógica de los Estados liberales, herencia de la tradición europea, que excluyen por medio de distintos dispositivos otras formas de asumir lo político, lo humano, lo ético y lo científico.

Palabras clave: movimientos sociales, Estado plurinacional comunitario, acciones sociales y políticas, pueblos originarios. 


\section{Political and Social Action of Native Peoples Towards the Configuration of the Plurinational Community State}

\section{Abstract}

This document derives from previous premises to demonstrate how constitutional changes in Bolivia materialized through social and political actions based on the ancestral practices and knowledge of native peoples, giving way to the construction of the Plurinational Community State. Thus, the analysis of the formation of Plurinational States in Latin America seeks to highlight the political and epistemic changes that some countries in the region are currently undergoing. These processes are unknown due to the lack of academic diffusion, which makes people reduce and confuse the term plurinational with others such as multiculturalism, pluriculturalism, or multiethnicity, obscuring the importance of this form of organization. In this sense, clarifying, analyzing, and understanding the political and epistemic positions of Plurinational States, allows us to evidence discourses and practices specific to countries where the presence of ethnic movements and social organizations shows a multiplicity of horizons at different levels, in opposition to the conditioning of the one-dimensional line of the logic of liberal States, inherited from the European tradition, which exclude through different devices other ways of assuming the political, the human, the ethical, and the scientific.

Keywords: social movements, Plurinational Community State, social and political actions, native peoples.

\section{Introducción}

Históricamente, los Estados latinoamericanos se han regido a partir de las disposiciones políticas liberales, que son producto de la herencia europea, buscando asumir formas organizativas unívocas que les permitan salir del anclaje social, político y cultural en el que se ha encontrado como subcontinente. Es claro que en los Estados de América Latina se ha tratado 
de definir un tipo deseable de sociedad a partir de discursos y prácticas, configurando ciudadanos que operen en las redes del sistema mundo capitalista y definiendo formas y taxonomías homogéneas que hacen viable y mantienen a este proyecto en esa dirección.

Es así como la creación de imaginarios sobre la modernidad en Estados con particularidades no modernas-industriales ha convertido a la mayoría de los países de Latinoamérica en estamentos inconsistentes, bajo permanentes cuestionamientos, por la incapacidad de articular las fuerzas sociales y modos organizativos de distintos grupos que coexisten en un mismo territorio. Desde la configuración de los Estados en Latinoamérica, una forma de cohesionar y unificar la población consistió en borrar las diferencias de todo tipo, con el propósito de llegar a la unidad y, así, aplicar modelos exógenos, para conformar un tipo deseado de nación. A su vez, otras situaciones coyunturales durante el siglo XIX y XX, como la concentración de la tierra en reducidos sectores, la explotación desmedida de los recursos naturales fijada por la lógica económica neoliberal,, la privatización de estos recursos (apropiando sectores geopolíticamente estratégicos) y la marginalización por medio de dispositivos de dominación, han desencadenado distintas formas de resistencia a través de movimientos y organizaciones sociales de tipo étnico, que no solo buscan el reconocimiento por parte de los Estados, sino que buscan generar dinámicas de cambio estructural por medio de luchas políticas y epistémicas, con el propósito de oponerse al sistema imperante y proponer formas alternativas en la creación de Estados.

La construcción de proyectos epistémicos, políticos y sociales en América Latina durante los últimos años ha estado sujeta a los nuevos ordenamientos constitucionales de algunos Estados, a partir de la presión de movimientos étnicos y sociales que han modificado el panorama geopolítico de continente. En este panorama, Bolivia es un ejemplo 
contundente de estos proyectos y movimientos. La propuesta de la Nueva Constitución boliviana, ratificada el 25 de enero de 2009 a partir del voto popular, señala en su preámbulo la construcción colectiva de un Estado plurinacional comunitario basado en la unidad, la armonía, la complementariedad y la reciprocidad y en los principios ético-morales de los pueblos indígenas y originarios de los Andes. Es decir, ama quilla, ama llulla, ama suwa (no seas flojo, no seas mentiroso ni seas ladrón), suma qamaña (vivir bien), ñandereko (vida armoniosa), teko kavi (vida buena), ivi maraei (tierra sin mal) y qhapaj ñan (camino o vida noble) (Nueva Constitución Política del Estado, 2009, art. 8) constituyen elementos formativos que los movimientos sociales y étnicos bolivianos han depositado en la actual carta magna, en búsqueda de una sociedad plural con la finalidad de dejar en el pasado el Estado colonial, republicano y neoliberal. Es así como en este proceso la interculturalidad y la plurinacionalidad se constituyen en elementos que posibilitan articular y relacionar el Estado moderno con un pensamiento propio boliviano, existente antes de la formación de la república.

En este sentido, los alcances de la Nueva Constitución Política del Estado solo fueron posibles por las acciones colectivas de los movimientos sociales, propiamente de tipo étnico, los cuales han dinamizado prácticas y discursividades de resistencia, manteniendo vigente el pensamiento indígena y comunitario en la configuración de un Estado plurinacional. Por tal razón, la siguiente ponencia evidencia cómo las condiciones coyunturales del Estado boliviano crearon una serie de situaciones para que los movimientos sociales consolidaran, por medio de distintas formas de resistencia, un proyecto alternativo de nación materializado en la Asamblea Constituyente. De igual manera, aquellos cambios sustentados en el Sumak kawsay y la vida comunitaria direccionaron el horizonte político de los 
pueblos originarios, en su búsqueda por posicionar un modelo que partiera de la realidad de las comunidades.

\section{Bolivia: multiplicidad de lógicas}

Históricamente, Bolivia, como los demás Estados latinoamericanos, se ha regido a partir de disposiciones políticas liberales, resultado de la herencia europea, trazando formas organizativas unívocas para llegar algún día a los ideales de desarrollo y progreso definidos por los países "del primer mundo". Para ello, es necesario entender la complejidad estructural de Bolivia, ya que en este país coexisten desarticuladamente distintas lógicas de tipo político, social, económico y cultural, que ubican diversos regímenes civilizatorios. En este sentido, Álvaro García Linera señala que un régimen civilizatorio para el caso boliviano es un grupo de estructuras de orden material, político y simbólico que definen de forma diferenciada las funciones productivas, los procesos técnicos, los sistemas de autoridad, la organización política y los esquemas simbólicos con los que las colectividades dan coherencia al mundo, afirmando que existen cuatro grandes regímenes civilizatorios en este país (García, 2003).

El primero, la civilización moderna industrial, se caracteriza por mantener una lógica acumulativa basada en la configuración de individuos competentes dentro del sistema industrial mercantil. Esta lógica exige sujetos que preponderen lo individual sobre lo colectivo, pasando por encima de las estructuras tradicionales comunitarias. El segundo régimen se basa en la "economía y cultura organizada en torno a la actividad de tipo doméstico, artesanal o campesino" (García, 2003, p. 74), al interior de lógicas asociativas o gremiales, en este régimen se ubican pequeños propietarios del sector campesino, artesanal e informal. El tercero es el régimen comunal, que pone sus instituciones y formas organizativas políticas y sociales al servicio de lo colectivo, basado en el aprovechamiento 
comunal de la tierra a partir de actividades técnicas y tecnológicas propias. Este régimen civilizatorio considera, a diferencia del primero, la tradición y la historia comunitarias como elementos formativos de lo individual. La civilización amazónica es el cuarto y último régimen, "basada en el carácter itinerante de su actividad productiva, la técnica anclada en el conocimiento y laboriosidad individual y la ausencia de Estado" (García, 2003, p. 74). En este sentido, hay que tener en cuenta que:

Casi de las dos terceras partes de los habitantes del país se hallan en alguno de las últimas tres franjas civilizatorias o societales. Es claro que este es un modelo conceptual que no excluye vínculos, cruces e hibridaciones complejas, producto de la colonización, entre estos cuatro bloques civilizatorios. Igualmente es importante tomar en cuenta que estas civilizaciones, con excepción de la última, atraviesan no solo la ciudad y el campo, sino también a pueblos indígenas y no indígenas. (García, 2003, p. 74)

Esta interrelación se presenta en los ámbitos sociales y culturales, ya que en el ámbito político nacional el primer régimen civilizatorio ha representado la totalidad de la población boliviana, dejando de manifiesto la formación de un Estado monoorganizativo a través de las disposiciones políticas liberales, es decir, este es el régimen de los partidos políticos, la división de poderes y la separación de la política y la economía, entre otras prácticas. Estas se consideran, desde los gobiernos neoliberales, como prácticas necesarias y resultantes para la inserción del proyecto capitalista en países en "vía de desarrollo". Estas disposiciones organizativas que dirigen a todos los Estados latinoamericanos entran en choque cuando, en países como Bolivia, "la mayoría de la población sumergida en estructuras económicas cognitivas y culturales no industriales, y encima detentadoras de otras identidades culturales y lingüísticas, es portadora de otros hábitos y técnicas políticas resultantes de su propia vida material y técnica" (García, 2003, 75). De ahí 
que, para el Estado, estas estructuras sean limitantes para llevar a cabo un proyecto social, político y cultural articulado con las disposiciones del sistema imperante. Es importante señalar que, en Bolivia, como en algunas regiones de los países de Latinoamérica, existen estructuras organizativas anteriores a la formación de la república, las cuales poseen otras lógicas de funcionamiento respecto al Estado moderno.

En este punto, el Estado boliviano ha creado un imaginario de modernidad sin contar con las particularidades de los sistemas civilizatorios no modernos-industriales que los han convertido, como en la mayoría de los Estados latinoamericanos, en estamentos débiles, justamente, por la ausencia de fuerzas sociales y modos organizativos que actúen articuladamente con las dinámicas de las naciones. Lo que sitúa a Bolivia en una

Recurrente dualidad institucional del sistema político, liberal, partidario y legal, por una parte, enfrentado y asediado por el poder político real de los movimientos sociales y las organizaciones comunitarias, sindicales y barriales de la sociedad, por otro, es la manifestación de este desencuentro dramático entre lógica organizativa del Estado y la pluralidad de prácticas organizativas políticas de la sociedad (García, 2003, p. 76).

Esta dualidad ha ocasionado frecuentes crisis políticas, sociales y económicas a las que Bolivia, al igual que otros países de la región, se ha enfrentado constantemente, agudizándose notablemente en las últimas décadas, ya que los gobiernos de turno se han opuesto sistemáticamente a la participación de los sectores subalternos en el Estado, tratando "de reducir a los movimientos sociales en simples agregados o desmovilizarlos por medio de la represión" (Cuba, 2006, p. 60). De esta manera, la principal exigencia de los movimientos y las organizaciones en Bolivia fue la convocatoria a una Asamblea Constituyente que reestructurara la Constitución Política del Estado. Esto generó diversas reacciones entre la población, como asumir 
estrategias simbólicas, que fueron "las principales banderas de lucha de los movimientos sociales en Bolivia, que se expresó en un complejo escenario social con violentas movilizaciones sociales y bloqueos de caminos en todo el país" (Cuba, 2006, p. 60). Estas movilizaciones y demandas impulsaron la Guerra de Febrero (2002) y la Guerra del Gas (2003), lo que provocó, por exigencia de la población, la renuncia de dos presidentes constitucionales en menos de dos años. Estas coyunturas, como las que históricamente se ha enfrentado el pueblo boliviano, se fundamentan en situaciones críticas generadas por la implementación de modelos políticos y económicos exógenos a las necesidades de la población indígena, campesina y originaria, produciendo escenarios de exclusión, como lo describe el Manifiesto de la Asamblea Nacional de Organizaciones Indígenas, Originarias, Campesinas y de Colonizadores de Bolivia de la siguiente manera:

La fuga del excedente económico basado en la explotación de nuestros recursos naturales, la concentración de la riqueza en pocas manos, producto de la tenencia ilegal e inequitativa de la tierra y la usurpación histórica de nuestros territorios ancestrales, la exclusión política, económica y social de la que hemos sido objeto y la privatización de nuestros recursos naturales y sectores estratégicos nos han llevado a la pérdida de nuestra dignidad y soberanía, generando la miseria de nuestros pueblos indígenas, afrodescendientes y naciones originarias (Manifiesto de la Asamblea Nacional de Organizaciones Indígenas, Originarias, Campesinas y de Colonizadores de Bolivia, 2006, p. 2).

\section{La acción social como mecanismo de la configuración del Estado plurinacional comunitario}

Las condiciones coyunturales actuales agudizadas por las nuevas configuraciones mundiales de tipo económico y político han generado dinámicas de ruptura en la historia de Bolivia, que contextualizan la incidencia del movimiento indígena y campesino en las dinámicas 
nacionales. En este orden de ideas, hacia la década de los ochenta se generaron dos fenómenos que también marcaron la forma y el accionar de los movimientos y de la población en general en Bolivia: el ingreso del neoliberalismo al país y el aumento de la producción de hoja de coca, que configuró aquella forma de cultivo como una de las más importantes del país.

Para la década de los noventa, la situación se volvió más compleja dado que la globalización empezó a poner en evidencia, sin afirmar que antes no existieran, las desigualdades e inequidades de la población boliviana, que, con la fuerza de las dinámicas propias del mercado y los procesos capitalistas, acrecentaron la pobreza del campesinado y relegaron a la población indígena. Este proceso, conforme al régimen de la coca de finales de los ochenta, generó represión y encarcelamientos injustificados a las personas que se vincularon con dicho proceso. Por otra parte, las guerras del Gas y del Agua representan la organización de la población para defender sus recursos y, sobre todo, evidencian uno de los elementos que se ha erigido a lo largo de la historia, no solo boliviana, sino latinoamericana: el territorio, que constituye la piedra angular de los movimientos sociales de tipo étnico con un corte reivindicativo.

Algunos de los acontecimientos anteriormente nombrados se convierten en las bases de la formación de movimientos sociales, como producto, incluso, de la organización de clase; pues, son los grupos campesinos, indígenas, mineros, estudiantiles y pensionados los que izan las banderas de la lucha y los que, a través de diferentes medios, manifiestan sus intereses, inconformismos, demandas y reivindicaciones frente a la sociedad y los gobiernos que los han subsumido en el olvido.

Dentro de esa amplia gama de acontecimientos a través de los cuales se materializan las formas de acción de la población organizada, se pueden encontrar las manifestaciones generales, los bloqueos a carreteras, los paros 
y las protestas, con los cuales se pretendía no solo dar a conocer una postura $\mathrm{y}$ vincular a diferentes sectores y grupos sociales, sino crear conciencia frente a las organizaciones estatales y la sociedad en general de las situaciones que se estaban presentando: la represión y el avance indiscriminado de las doctrinas capitalistas neoliberales, que en un país con tan profundas contradicciones, es claro que generan más inequidades y desigualdades.

Se dio también de creación, nacimiento y consolidación de organizaciones, centrales obreras, gremios y, posteriormente, partidos, que, desde un punto de vista normativo en un escenario democrático, recogieron la voluntad y el consenso general, pero, con el tiempo, pueden llegar a tener contacto con los vicios propios de la burocratización del poder y así corromper los ideales bajo los cuales fueron creados. Dentro de las consecuencias y los contextos que surgen después de todos estos elementos, es menester nombrar, resaltar y darle importancia a dos de los principales componentes que caracteriza la organización y la consolidación de los movimientos sociales en Bolivia: la emergencia de las bases populares y la consolidación de la multitud como el cuerpo por el cual se gestan las manifestaciones que visibilizan los conflictos y las reivindicaciones de la población (Córdova y Vargas, 2003; Gómez, Idrobo, Rincón y Restrepo, 2020; Idrobo y Orrego, 2020; Idrobo, 2012).

Junto a estas dinámicas, se encuentra el proceso de descentralización, donde aquellas expresiones locales que antes podían ser consideradas como aisladas, ahora hacen parte de un todo, una unidad que políticamente se encuentra fuerte para poder participar a nivel general, conservando los particularismos que las definen. Así, las transformaciones urbanas y rurales que dieron lugar a las manifestaciones y las reformas estatales, ya que tanto las poblaciones de las ciudades como las del campo se encuentran en igualdad de importancia y participación (casos como El Alto, La Paz, 
Cochabamba y Chaparelo lo demuestran), dieron cuenta de una conjunción donde se manifestaron geográfica e históricamente los fenómenos, conflictos, cambios y soluciones que configuraron los movimientos sociales y construyen la historia misma del país.

Como ejemplo de organización y construcción de identidad, comunidad y movilización, se encuentra la ciudad de El Alto, "una ciudad marginada y desoída, pero a la vez rebelde y combativa” (Puente y Longa, 2007, p. 96). En el proceso de configuración que vivió esta ciudad están presentes las condiciones y los elementos que constituyen la lucha en Bolivia: El Alto pasa a ser una ciudad donde se mezclan los estilos rurales y urbanos, en el aspecto de la construcción, y, económicamente, se presenta el fenómeno del "autoempleo" y empleo informal. También, se retoma el modelo organizativo de los ayllus: se conforman las juntas vecinales (y su federación) como otra forma de organización y control cívico de la comunidad, articulándose a las movilizaciones sociales y a las luchas que acaecieron en la Guerra del Gas. Por último, al interior de las dinámicas culturales y educativas, se crea la Universidad del Alto y se da el nacimiento de movimientos contraculturales liderados por jóvenes que legitiman la identidad construida en este período (Puente y Longa, 2007).

Teniendo en cuenta las anteriores consideraciones, se puede evidenciar la articulación de la misma población y de los movimientos que ellos y sus líderes encarnan, bajo distintos proyectos, configurando mecanismos y alternativas para la organización y defensa de las reivindicaciones y demandas de las culturas originarias y poblaciones sometidas a marginalizaciones de todo tipo.

Es en estos términos que se entiende el planteamiento de Raúl Prada cuando nos habla de las consecuencias de las significaciones históricas y políticas de los movimientos y la población en Bolivia: la reivindicación y la repercusión, respectivamente. Lo anterior fue posible porque las 
manifestaciones y luchas construyeron el andamiaje con el que los movimientos campesinos, indígenas y urbanos ahora se vinculan a la política de forma activa y decidida. Las reformas constitucionales en la educación y la descentralización generaron un impacto en el campo cultural y, por consiguiente, en el político, pues la incorporación de los elementos tradicionales relacionados con el pasado. como la historia y el territorio, y las prácticas políticas de participación dieron cuenta de la construcción de un Estado plurinacional comunitario incluyente. Si bien esta forma organizativa tiene falencias y debilidades en contextos como el latinoamericano, el planteamiento principal es la formalización de la diversidad desde las bases sociales, fuera de las disposiciones neoliberales. Es así como la diversidad, de tipo cultural, social, política y económica, posibilita que la heterogeneidad y la participación de todos los sectores de la sociedad sean factores constitutivos de las naciones.

\section{Movimientos sociales y Asamblea Constituyente}

Como resultado de las grandes movilizaciones en Bolivia, en el año 2005, se vivió uno de los momentos de ruptura más importantes en la nación andina. Esta fecha marca la culminación de un proceso y el inicio de una nueva etapa en su historia. La llegada de Evo Morales Ayma al poder define el arribo de un gobierno de corte "progresista", de los que se empezaron a gestar en algunas naciones latinoamericanas (Venezuela, Brasil, Ecuador, Argentina), y la materialización de la lucha que por varios años libraron los movimientos sociales, las comunidades indígenas y campesinas y la población en general. Sin embargo, este proceso, como se enunció anteriormente, parte desde las distintas luchas de resistencia lideradas por las poblaciones históricamente subyugadas, otorgándole a la Asamblea Constituyente, en búsqueda de posicionar un estado plurinacional 
comunitario, las herramientas para continuar manteniendo el pensamiento indígena al interior de un escenario más amplio como el Estado.

En este sentido, antes, durante y después del 2005, se han creado las condiciones para la formación de un caldo de cultivo donde entran a participar actores, espacios, movimientos, comunidades, eventos, contradicciones y toda una serie de elementos, que dan cuenta del tránsito hecho por la población y el movimiento liderado por Morales hacia el poder y, por consiguiente, los retos y divergencias que de él emanan. Es pertinente aclarar que más allá de caer en la figura caudillista de Morales en Bolivia, lo que se posiciona es todo un cambio epistémico, puesto que a partir de este momento lo indígena pasa de ser una instancia de reivindicación a configurarse en modelo de Estado.

Para ello, los aportes de distintos teóricos de este país, a través de diferentes categorías de análisis, ofrecen elementos que denotan la configuración y consolidación de un movimiento popular y los retos que de este se desprenden frente al manejo de un Estado que, como el boliviano, carga con un largo historial de particularidades y contingencias derivadas de su carácter heterogéneo. En este sentido, la Asamblea Constituyente es el resultado de la movilización social en Bolivia. En ella, destacan dos momentos de gran importancia para la configuración del movimiento como un poderoso dispositivo de reclamación y reivindicación: la Marcha por el Territorio y la Dignidad (1990) y la de los pueblos de tierras bajas por la Asamblea Constituyente (2002), ambas marchas evidenciaron el deseo y la voluntad de las comunidades indígenas de que ellas mismas y su territorio fueran reconocidos. De esta forma, las organizaciones se proyectaron hacia una participación política más amplia, con el propósito de pasar los límites impuestos por los partidos políticos y posicionar, como en el caso de la marcha de 2002, la demanda de una reforma estatal que incluyera todas las transformaciones mencionadas. Adicionalmente, los movimientos ya habían 
logrado el reconocimiento de la trayectoria de los pueblos indígenas y de sus mecanismos de encuentro y organización.

De esta manera, las distintas coyunturas, por ejemplo, las guerras del Agua y del Gas, fueron el resultado del inconformismo de la población frente al manejo que el gobierno hizo de los recursos naturales y sus intenciones de venderlos a empresas transnacionales. Ambas "guerras", como se enunció anteriormente, crearon el escenario político para la renuncia de dos presidentes, la búsqueda de la nacionalización de los hidrocarburos y la defensa de los recursos naturales y el medio ambiente, en pro del establecimiento de estos y del territorio como dos de los elementos fundamentales para la construcción de nación. Todo esto contribuyó también a resignificar conceptos tradicionalmente cerrados y homogéneos para el país, como la política, que, a partir de entonces, pudo entenderse como un espacio abierto de encuentro y deliberación colectiva. El papel que cumplieron los movimientos y las movilizaciones sociales posibilitó, sobre todo, "que se [presentaran] a sí mismos como la fuente fáctica de un modo diferente de hacer política, con posibilidades reales de enfrentar las maneras partidario-electorales que hasta ese momento habían sido impuestas como las únicas posibles" (Chávez y Mokrani, 2007, p. 63).

\section{Ideologías y racionalidades en Bolivia}

Lo anterior evidencia, tomando como ejemplo a Bolivia, la manera en que las naciones Latinoamericanas se han constituido como híbridos culturales y sociales, justamente, por medio de diferentes contingencias históricas y políticas, resultado de la combinación de una modernidad abrumadora adherida a países con poblaciones milenarias. Con el devenir del tiempo, las contradicciones y convergencias que se generan a raíz de las distintas coyunturas de este tipo han configurado diversas dinámicas de resistencia en las naciones que poseen un origen milenario fuerte, donde el pasado y las 
tradiciones siempre han estado en conflicto con la modernidad. Al reflexionar sobre los distintos escenarios históricos, políticos y sociales en Bolivia, es pertinente enunciar las racionalidades que han convergido en las prácticas y discursividades evidenciadas a través de una multiplicidad de ideologías presentes en esta nación, las cuales se describirán brevemente, ya que estas definieron el rumbo del país durante los últimos cien años. La primera es el anarquismo, presente a finales del siglo XIX. Esta ideología tomó fuerza en los años 30 y 40 del siglo siguiente, enfocada en "articular las experiencias y demandas de sectores laborales urbanos vinculados al trabajo artesanal y obrero en pequeña escala y al comercio" (Linera, 2007, p. 1). La segunda ideología es el indianismo de resistencia, que surgió también a finales del siglo XIX, donde el movimiento indígena (de mayoría aymara) combinó de manera fragmentada la negociación de las autoridades originarias con la sublevación local de la región. A mediados del siglo XX, se incorpora en el escenario político el nacionalismo revolucionario, que trajo consigo nuevas características y dinámicas al Estado boliviano, ya que vinculaba sus instituciones para obtener y mantener el poder y la estabilidad nacional. Así, el Movimiento Nacional Revolucionario (MNR) hizo que sus planteamientos partidarios enfocaran toda una concepción estructural emitida desde el Estado, proporcionando una reforma moral e intelectual que originó una hegemonía político-cultural de 35 años en el país. El nacionalismo revolucionario se convirtió, pues, en una de las construcciones políticas más importantes de la nación boliviana en el siglo XX.

Paralelamente al surgimiento del nacionalismo revolucionario y su constitución como partido y detentor del poder, los círculos sociales empezaron a relacionarse con el marxismo y a incluirlo en sus agendas y debates, es decir que el marxismo se adhirió a la cultura política nacional y buscó convertirse en una ideología hegemónica. Esta fase inicial marxista estuvo marcada por el énfasis en la lucha política e implicó una evidente 
recepción en el mundo laboral, donde la primacía de la actividad industrial configuró la identidad obrera y, además, la ubicó sobre todas las demás identidades presentes en la sociedad, mostrando cómo el sometimiento real del trabajo al capital supone un perjuicio para las masas. De esta manera, surgió la ideología proletaria . Esta se convirtió, "sin lugar a dudas, [en] una ideología de modernización industrial del país en lo económico, y de consolidación del Estado nacional en lo político" (Linera, 2007, p. 2).

A mediados de los años 80, se dio inicio al fortalecimiento de la identidad indígena y campesina, donde el marxismo asistió al desprendimiento de la fuerza y la identidad obrera organizada a través de sindicatos por el posicionamiento del discurso étnico. El marxismo se erigió, entonces, como una ideología que incluía las dinámicas económicas industriales, sin embargo, falló en la inclusión de la amplia gama de identidades constitutivas del universo social boliviano, por dar prioridad a la obrera.

La quinta gran ideología es el indianismo, que, así como las otras enunciadas anteriormente, ha sido vulnerable y susceptible a cambios internos, configuraciones diversas y aplicaciones variadas durante todo su proceso de construcción. A finales del siglo XIX y principios del XX, hubo un indianismo de resistencia, no obstante, para el indianismo que nace en la segunda mitad del siglo XX, la base y objetivos van a ser muy distintos. Como tal, este indianismo nace en el contexto de los años 70, cuando comienza el proceso de reinvención de la indianitud como proyecto político, que se va a desarrollar por medio de tres períodos. El primero de ellos, como ya se mencionó, inicia en los años setenta, cuando la ideología indígena empieza a tomar fuerza, se distancia de los discursos obreros y marxistas y ayuda a construir la identidad indígena nacional. En este momento, surge una intelectualidad aymara escolarizada, que va a tener acceso a los circuitos académicos manteniendo una pronta relación con movimientos y organizaciones sindicales. 
En esta perspectiva, el desarrollo de varias vertientes dentro del mismo discurso, como la sindical, la política partidaria y la corriente académica, evidenció la forma en la que el propio movimiento halló caminos para su configuración, teniendo en cuenta su propia heterogeneidad. Su desarrollo continuó en los años 8o, en los que se dio una clasificación adicional, enfocada siempre en el fortalecimiento del discurso y la identidad indígena, es decir, "el indio y el indianismo devienen en un discurso estrictamente nacional, el de la nación indígena aymara" (Linera, 2007, p. 7).

Este enfoque abrió paso a tres corrientes. La primera enfatizó en la dimensión culturalista, donde se resaltaron los aspectos culturales tradicionales como la música y la religiosidad. La segunda obedeció a un orden integracionista, la cual propendió por la reivindicación indígena frente al Estado, criticando los tipos de fragmentación ciudadana, ya que ésta se dividía en primera y segunda clase, definidos por las condiciones raciales; esta fragmentación justamente generaba los problemas para ejercer la ciudadanía. Por último, la tercera era una corriente nacionalista indígena, en la que el indígena, además de ser un sujeto político, era considerado un ser con poder. En este proceso, se crea un paraindigenismo que radicaliza la posición de la nación indígena, utilizando, por ejemplo, narrativas heroicas o guerreras para resaltar los propios aspectos que históricamente los convierten en sujetos de poder.

El segundo periodo del indianismo empieza a gestarse a finales de los años 80 y está caracterizado por una aparente consideración de parte del Estado (en cabeza del nacionalismo revolucionario) del discurso étnico, manifestada en la aparición en escena de identidades culturales diversas y en el desplazamiento de la lucha hacia las zonas cocaleras del Chapare, lo que vincula nuevos movimientos, organizaciones y discursos a las demandas que ya se venían realizando. Este período se caracterizó como un momento de "cooptación estatal", pues se emitieron una serie de leyes de inclusión, 
como la Ley de Participación Popular, que pretendía generar y crear mecanismos para la incorporación de población en la política, pero, que realmente fue un "mecanismo sofisticado" de cooptación y presión de líderes populares, que eventualmente creó fragmentación dentro del movimiento y la misma comunidad (Linera, 2007).

Un último período planteado, el tercero, se da en la década de los 90, en la que el indianismo empieza a tomar fuerza y a constituirse en "la concepción del mundo de corte emancipativo más importante e influyente de la actual vida política [...] y el núcleo discursivo y organizativo de lo que hoy podemos denominar "la nueva izquierda" (Linera, 2007, p. 8). Este período se caracteriza por los inicios de la capacidad de sublevación comunitaria y el establecimiento de las masas y los movimientos populares como las bases de las organizaciones y movimientos sociales que se encuentran en lucha y disputa. Así, empiezan a generarse conflictos entre las ciudades y el campo, por los desniveles económicos generados por las políticas del neoliberalismo. Para este momento, como se sugirió en los periodos anteriores, hay también dos vertientes: una moderada, vinculada con los sindicatos campesinos cocaleros donde surge el Movimiento al Socialismo MAS, y una radical, que busca una indianización total de las estructuras de poder,. Estas vertientes, aunque son diferente, convergen en el mismo escenario político, pues, comparten trayectorias políticas similares.

En este punto es preciso considerar si este proceso se puede definir como un "giro a la izquierda", como se mencionó anteriormente. Para ello, se recurre a los estudios de Mignolo (2005) sobre Bolivia, específicamente, a partir del rastreo que hace en su libro La idea de América Latina, ya que brinda elementos para profundizar en la discusión. En este sentido, existe un claro posicionamiento de dos tendencias en la intelectualidad boliviana. La primera tiene un enfoque progresista y se aferra a las tradiciones académicas europeas. La segunda está asociada a la intelectualidad quechua 
y aymara e incluye a la academia mestiza en el contexto de las cosmologías indígenas; está claro que, por el hecho de ser intelectualidad, proviene en parte de la epistemología europea. Es necesario tener en cuenta este punto, ya que las dos tendencias se configuran como opciones: una, la aymaraquechua, proveniente de las dinámicas propias indoamericanas; la otra, una opción euroamericana, desde la perspectiva castellana-francesa-inglesa.

Es en este punto donde "la izquierda" toma dos rumbos. Por una parte, en el enfoque progresista, el primero, se entrecruzan el nacionalismo, el marxismo y el indianismo bajo un mismo proyecto: el Movimiento al Socialismo (MAS), en el que no se define una ideología en especial. El MAS surge en el momento en el que el movimiento sindical cocalero se encuentra bajo una influencia marcada del marxismo, conservando los ideales de la revolución de 1952, desarticulados cuando el Movimiento Nacional Revolucionario (MNR)pasó a ser parte de la maquinaria política boliviana tradicional, convirtiéndose en un partido a merced de la lógica neoliberal como sucedió durante el gobierno del expresidente Gonzalo Sánchez de Losada, antes de la entrada de Evo Morales al poder. Por otra parte, el segundo enfoque, que se consolida en un referente claro también del MAS, el indianismo se posiciona por encima del nacionalismo y el marxismo, claro está, sin desconocerlos y, mucho menos, borrarlos de su plataforma política; no obstante, desde los pueblos y naciones indígenas que hacen parte fundamental del partido el indianismo significó la "liberación" de la ideología marxista (Mignolo, 2005). Teniendo en cuenta que la intelectualidad eurocéntrica simpatizante del gobierno de Evo Morales busca desdibujar los límites entre las tres ideologías, para los intelectuales indígenas, el indianismo es la bandera de lucha a potenciar. Desde este último enfoque, la izquierda cobra otro sentido (si se quiere llamar de este modo), ya que esta propuesta va en una dirección distinta a las planteadas por partidos socialistas en la región. En países como Brasil, Chile, Venezuela 
y Cuba, la vía modernizadora va en contra de lo que significa "el desarrollo" para el indianismo.

Es así como, para autores como Ramonet, el "giro a la izquierda" en Bolivia se presentaba por medio del acercamiento del movimiento indígena a la "izquierda latina", dinámica contraria para Mignolo. Es decir, en esta perspectiva, la izquierda tradicional, a partir de este proceso, puede reconocer que la "revolución" se configura por medio de la incidencia de todos los sectores, incluidos los étnicos. De igual manera, hay que señalar que el proyecto indígena discrepa en gran medida con la izquierda tradicional, porque los dos enfoques provienen de memorias, sentires y construcciones epistémicas distintas. El término "izquierda" parte de la sensibilidad y memoria francesa y está asociado a que, durante la revolución de 1789, en la izquierda se ubicaban los parlamentarios que escudaban la ideología del "progreso", opositores de los terratenientes, las élites financieras y los emergentes industriales situados en la parte derecha del parlamento (Mignolo, 2005). A su vez, durante el siglo XIX, primero con Saint-Simon y después con Marx, la "izquierda" se ligó con el socialismo y, posteriormente, con el comunismo. El concepto de izquierda llegó a América Latina a través de los inmigrantes. Los descendientes de estos fundaron partidos políticos de "izquierda", una izquierda traída de Europa, permeada de las ideas liberales y republicanas. Es así como, bajo este contexto, para "la izquierda", las naciones indígenas y afro nunca existieron, en la medida en que aquellos grupos étnicos tan solo se veían como campesinos sindicalizables, esta mirada ignoraba a las demandas propias de estas naciones. Es este sentido, el balance de García Linera sobre la izquierda boliviana, definida a partir de la anterior afirmación, establece que aquella tendencia política de estar de espaldas a la situación étnica mantiene una posición ortodoxa, impidiendo el diálogo con las naciones indígenas. 
De esta manera, más que ubicar la experiencia boliviana como un "giro a la izquierda”, materializado en el proceso político de los sectores indígenas, campesinos y originarios, lo que se busca es posicionar horizontes propios a partir de formas alternativas que potencien el pensamiento y las prácticas propias, claro está, sin imponer su visión de manera radical y ortodoxa.

\section{Construcción epistémica, política e ideológica de los movimientos indígena, campesino y de colonizadores}

Las situaciones y momentos coyunturales en Bolivia han generado que los movimientos sociales y las organizaciones indígenas y campesinas actúen y se pronuncien de distintas maneras. Una de ellas fue la "gran marcha campesina e indígena desde Santa Cruz de la Sierra, hasta la Paz, demandando la convocatoria de la Asamblea Constituyente para refundar Bolivia” (Díez, García, 2007, p. 5). Esta movilización tuvo como resultado la Ley Especial de Convocatoria a la Asamblea Constituyente, dictada en marzo de 2006. Las organizaciones comunitarias, al momento de instalarse la Asamblea Constituyente (esta convergencia de organizaciones también fue conocida como el Pacto de Unidad) el 6 de agosto de ese año, presentaron de forma colectiva el documento Asamblea Nacional de Organizaciones Indígenas, Originarias, Campesinas y Colonizadoras de Bolivia: Propuesta para la Nueva Constitución Política del Estado.

Este documento recoge la propuesta política e ideológica de las siguientes organizaciones: la Confederación Sindical Única de Trabajadores (CSUTCB), el Consejo Nacional de Ayllus y Markas del Qullasuyu (Conamaq), la Confederación de Pueblos Indígenas de Bolivia (CIDOB), la Confederación Sindical de Colonizadores de Bolivia (CSCB), la Federación Nacional de Mujeres Campesinas de Bolivia "Bartolina Sisa” (FNMCBBS), la Coordinadora de Pueblos Étnicos de Santa Cruz (CPESC), la Confederación de Pueblos Étnicos Moxeños de Beni (CPEMB), el Movimiento Sin Tierra de 
Bolivia (MTS) y la Asamblea del Pueblo Guaraní (APG). Estas

organizaciones establecen "otro" tipo de conformación estatal que cuestiona y replantea el modelo hegemónico llevado hasta el momento, demostrando el posicionamiento de los pueblos como actores colectivos políticos y sociales a nivel local, regional y nacional. Estas no solo tienen la finalidad de mantener las estructuras organizativas al interior de cada comunidad, sino de llevarlas y proponerlas como modelo nacional. Un modelo nacional basado en la unidad y la participación de todos los bolivianos y bolivianas, confrontando las disposiciones del mundo moderno y del neocolonialismo y, a su vez, modificando y proponiendo "otras" categorías de la geopolítica del conocimiento imperante. En este sentido, el documento de las Organizaciones Indígenas, Originarias, Campesinas y de Colonizadores plantean que en:

Bolivia, como los demás estados de América Latina, ha construido un modelo liberal caracterizado por la imposición de la cultura occidental, que ha marginado y debilitado nuestras culturas originarias y nuestros sistemas políticos y jurídicos. La división político administrativa ha impuesto fronteras que han roto las unidades territoriales tradicionales, resquebrajando la autonomía y control sobre la tierra y recursos naturales. Se han impuesto un sistema jurídico uniforme $[\mathrm{y}]$ modelos de gobierno y administración de justicia ajenos, que favorecen los intereses del mercado y privan a los pueblos de sus medios de subsistencia y, por lo tanto, deterioran nuestra calidad de vida. (Organizaciones Indígenas, Originarias, Campesinas y de Colonizadores, 2006, p. 2)

De esta manera, se evidencian las condiciones desfavorables en las que se ha encontrado la población boliviana, tomándolas como punto de partida para que los grupos subalternos luchen en contra de la colonialidad y el imperialismo. Estos grupos ponen en tela de juicio la conformación de estructuras monoorganizativas y la implantación de un Estado uninacional, repensando categorías que posiblemente contribuyan a generar procesos de 
transformación no solo en Bolivia, sino en los demás Estados de América Latina. Es así como los conceptos propios guían al proyecto social y político del “otro” y demarcan las dinámicas y prácticas de la vida social de los indígenas, campesinos, afrodescendientes, colonizadores y, por lo tanto, de la totalidad de las bolivianas y los bolivianos, por medio del reconocimiento y la construcción de un Estado plurinacional comunitario, entendido por las organizaciones como:

Un modelo de organización política para la descolonización de nuestras naciones y pueblos, reafirmando, recuperando y fortaleciendo nuestra autonomía territorial, para alcanzar la vida plena, para vivir bien, con una visión solidaria, [y] de esta manera ser los motores de la unidad y el bienestar de todos los bolivianos, garantizando el ejercicio pleno de todos los derechos. (Organizaciones Indígenas, Originarias, Campesinas y de Colonizadores, 2006, p. 2).

En este sentido, otro elemento que se aprecia en la definición del Estado plurinacional es su carácter unitario, refiriéndose a la integridad territorial del país en contra de la postura de sectores industriales de Bolivia, que, a partir de su oposición al gobierno de Evo Morales Ayma, se han propuesto formar bloques, como la denominada "media luna" (prefecturas de Santa Cruz de la Sierra, Sucre, Beni, Pando y Tarija), que buscan por medio de la violencia física y simbólica conformar discursos y acciones separatistas, porque el proyecto de la actual constitución toca puntos álgidos, como la exagerada tenencia de tierra y la acumulación del capital en pocos sectores industriales.

De esta manera, las autonomías territoriales campesinas, indígenas y originarias se perfilan como una vía para la autodeterminación de los pueblos y las naciones, definiendo sistemas sociales, económicos y jurídicos a partir de políticas comunitarias propias, para que, por medio de la reafirmación de estas nuevas estructuras de gobierno, se reconozcan y 
respeten maneras diferenciadas de vida en el uso del territorio y el espacio. Claro está que este tipo de conformación autónoma propia se erige como un proyecto donde a partir de la diferencia se conforma la unidad y el bienestar de la población boliviana, en este proyecto se articulan los distintos niveles de la administración pública nacional, proyecto totalmente distinto a ese de los sectores que asumen la diferencia como una amenaza a sus intereses particulares.

Es en este punto en el que la interculturalidad se convierte en la base para asumir una política encaminada a visibilizar la coexistencia y participación de las distintas nacionalidades y pueblos de Latinoamérica bajo la estructura plurinacional del Estado. La acepción ideológica, política y conceptual de la interculturalidad, enunciada por la Confederación de Nacionales Indígenas del Ecuador, es un buen ejemplo para demostrar que la propuesta de las organizaciones indígenas, campesinas y originarias es un proceso de cambio en la región. Este proceso "entiende" que

El principio de interculturalidad respeta la diversidad de los pueblos y nacionalidades indígenas y demás sectores sociales, pero a su vez demanda la unidad de estas en el campo económico, social, cultural y político, en aras de transformar las actuales estructuras y construir el nuevo Estado Plurinacional, en un marco de igualdad de derechos, respeto mutuo, paz y armonía entre nacionalidades. (Conaie, 1994, p. 13)

\section{La interculturalidad y la plurinacionalidad desde la teoría decolonial en América Latina}

La configuración de Estados plurinacionales en algunos países de América Latina, ocasionada por la fuerte influencia de los movimientos y organizaciones sociales, generó cambios constitucionales con un trasfondo epistémico. Este trasfondo epistémico ha sido analizado ampliamente por Walsh y Mignolo, ya que una buena parte de las apuestas teóricas de estos 
autores se enfoca en los procesos políticos, sociales y culturales de Ecuador y Bolivia. Esta teoría parte de reconocer las condiciones de producción de los discursos sobre lo subalterno y las formas en que estos se han complejizado de acuerdo con exigencias políticas, históricas, sociales y culturales específicas, según las problemáticas propias de cada país del continente americano. De esta manera, el análisis de lo subalterno posibilitó la conformación de un grupo de estudios que problematizara esta temática en América, señalando de manera general las influencias teóricas en la construcción de lo subalterno y, además, reconociendo la amplia influencia de todos los sectores académicos, políticos y sociales que participaron en la consolidación de esta perspectiva. Propiamente, para el caso de los entes territoriales construidos desde la colonia y la república en América Latina: los Estados, desde este enfoque teórico, la propuesta parte en evidenciar la des-nacionalización y des-territorialización del, justamente, Estado-nación. Estas propuestas buscan "mirar hacia atrás [y] reconsiderar aquellas formas prenacionales de territorializacion precolombina y colonial, [...] [sin olvidar que] también se necesita mirar hacia adelante para pensar en nuevas formas emergentes de subdivisión territorial"(Grupo Latinoamericano de Estudios Subalternos, 1998, p. 70), rastreando desde la perspectiva teórica lo plurinacional y lo intercultural en América Latina.

El contexto general en América Latina suscitó la imperiosa necesidad de proponer alternativas, desde lo académico, lo político y lo social, que intenten construir un mundo donde estén presentes todas las formas de pensar y actuar, sin darle preeminencia a ninguna, como se le ha dado históricamente a la visión occidental. Por esta razón, la teoría decolonial propone conceptos y estrategias para abordar lo subalterno en distintas perspectivas. Es así como, desde este enfoque, deconstruir los paradigmas de la nación y la independencia y des-nacionalizar y des-territorializar el estado-nación, a partir de "un trabajo arqueológico en los intersticios 
abiertos por las formas de dominación (ley y orden y poder militar o policial) e integración (aprendizaje y escolaridad)" (Grupo Latinoamericano de Estudios Subalternos, 1998, p. 72), significa situar al sujeto subalterno en la ruptura, en una que, justamente, se distancia de "modelos tradicionales de movilización vertical y de control social" y cuestiona sus formas hegemónicas de representación (Grupo Latinoamericano de Estudios Subalternos, 1998, p. 72).

$\mathrm{Al}$ reconocer la realidad latinoamericana, en términos de los nuevos ordenamientos económicos (sistemas transnacionales); políticos (el desmantelamiento de los regímenes autoritarios en Latinoamérica, el final del comunismo y el consecuente desplazamiento de los proyectos revolucionarios); sociales y culturales (nuevas dinámicas creadas por el efecto de los medios masivos), se busca formular y consolidar un grupo interdisciplinar e intersectorial que analice y profundice las problemáticas de Latinoamérica por medio de nuevas estrategias de investigación. Estrategias que partan de la presencia de los sujetos subalternos en la historia latinoamericana y reconozcan sus realidades. Así, lograr revisar epistemológicamente las ciencias sociales y las humanidades y reconceptualizar el pluralismo y la diversidad, con el propósito de pensar nuevas formas en las condiciones de subalternidad en América Latina. En esta perspectiva, retomando la discusión central en este último apartado, para los estudios decoloniales, la interculturalidad (como fundamento del Estado plurinacional) aboga por un cambio y una transformación de las estructuras de la sociedad, a través de prácticas contra-hegemónicas y de oposición a las históricamente acentuadas por la cultura dominante. La marginación, explotación y dominación de las comunidades indígenas, campesinas y originarias son consecuencias de la modernidad-colonialidad. En respuesta a estas coyunturas, surgen, desde la diferencia colonial, 
alternativas cimentadas en lógicas sociales, políticas, éticas, etc., distintas a las occidentales, lo que define Walsh como un "giro epistémico".

Estas respuestas, en oposición a la estructura dominante, tratan de "transgredir las fronteras de lo que es hegemónico, interior y subalternizado" (Walsh, 2006, p. 28), donde el Estado plurinacional y la interculturalidad son conceptos constituidos desde la diferencia colonial. Es decir, la lógica de estos conceptos implica "un conocimiento y pensamiento aislado de los paradigmas o estructuras dominantes; por necesidad (y como un resultado del proceso de colonialidad) esta lógica 'conoce' esos paradigmas y estructuras" (Walsh, 2006, p. 29). Es a través de ese conocimiento que se genera un pensamiento "otro", afectando y descolonizando tanto "las estructuras y paradigmas dominantes como la estandarización cultural que construye el conocimiento 'universal' de occidente" (Walsh, 2006, p. 29).

En este mismo sentido, se ubican las apuestas teóricas de Boaventura de Sousa Santos, cuando aborda los conceptos presentes en este apartado (plurinacionalidad, interculturalidad y poscolonialidad). El uso de estos conceptos en la discusión corrobora la apuesta teórica trabajada. Para este autor, la plurinacionalidad conlleva la refundación del Estado moderno, en él se combinan diferentes conceptos de nación; de esta forma, la interculturalidad es la forma como cada sociedad organiza su plurinacionalidad. Así, la poscolonialidad, siguiendo este orden de ideas, plantea que el colonialismo no terminó con la independencia de las naciones latinoamericanas. Esto se evidencia, por ejemplo, en el fuerte racismo que reina aún en el continente y en el hecho de que en quinientos años no se eligiera un presidente indígena en Bolivia, hasta el gobierno de Evo Morales, que constituye, a su vez, un ejemplo de innovación política. Así, podemos afirmar, primero, que el Estado no puede ser culturalmente neutro y, segundo, que debe primar una memoria donde exista una justicia histórica 
que no fundamente una discriminación, sino, que esté a favor de las poblaciones oprimidas. Dentro de estas condiciones, debe estar presente un "pluralismo jurídico", en el que subsista la diversidad de sistemas en un mismo Estado.

Dentro de este contexto, emerge también una constelación de poderes distintos que hacen referencia a las relaciones de poder (de todo tipo) presentes al interior de la sociedad, mediadas inicialmente por las relaciones de trabajo y por las consecuencias de la lógica del capitalismo neoliberal. En estas relaciones de poder, se asume al otro desde un punto de vista de superioridad, como método de fortalecimiento de la identidad (dominadora en este caso). Son en estos espacios donde surgen y se desarrollan las transformaciones sociales que se caracterizan por poseer, entre otros, los siguientes aspectos: nuevos lenguajes y nuevas y diferentes narrativas; nuevos actores y nuevas prácticas transformadoras; nueva formas y culturas de organización; una "neoterritorialidad"; una desmercantilización y el nacimiento de nuevas formas de economía; una lucha por la igualdad y el establecimiento de una educación popular más allá del saber científico.

Para la construcción de un Estado fuerte que soporte esta nueva idea de constitucionalismo experimental, como lo es la plurinacionalidad, se necesita de una flexibilidad jurídica, en la que no existan soluciones institucionales uniformes. Por lo tanto, es necesario y deseable un pluralismo jurídico que fomente el constante diálogo entre los distintos sistemas. Esta es la idea de institucionalidad desde esta mirada. La otra, la territorialidad, está relacionada con la forma en que las distintas organizaciones administrativas subsisten: tanto las organizadas políticamente, como aquellas de carácter originario. Ambas deben subsistir para crear un Estado plurinacional. Ambas deben, también, convivir democráticamente y mezclarse gradualmente, sin prisa ni inmediatez. 
Es así como "lo que es diverso no está desunido, lo que está unificado no es uniforme, lo que es igual no tiene que ser idéntico, lo que es diferente no tiene que ser injusto" (Santos, 2009, p. 60). De esta manera, se pretende enfatizar en la forma en que la cultura y la política y sus relaciones recíprocas constituyen un elemento primario en la construcción de los Estados plurinacionales. Así, los países con esta tendencia deben innovar políticamente y aplicar el constitucionalismo experimental, con una constituyente que de manera paulatina reforme ese Estado liberal heredado de la tradición occidental dominante y opresora. Adicionalmente, la voluntad del pueblo, perteneciente a una cultura amplia, debe estar en capacidad de integrarse y respetar las otras, siempre y cuando, la suya sea también respetada.

Para finalizar, los anteriores postulados contextualizan la discusión sobre lo plurinacional y la interculturalidad. De esta forma, nos alientan a continuar la búsqueda de categorías que evidencien las incidencias de los movimientos y organizaciones sociales de tipo étnico en los Estados de la región andina latinoamericana, posicionando el pensamiento indígena en el accionar político de las distintas naciones y comunidades originarias.

\section{Referencias}

Asamblea Constituyente República de Bolivia. (2008). Nueva Constitución Política del Estado.

Coordinadora Andina de Organizaciones Indígenas [CAOI]. (2008). Estados plurinacionales comunitarios. El Buen Vivir para que otros mundos sean posibles. Carlos Arrieta Editor.

Conaie. (1994). Proyecto Político de las nacionalidades y pueblos del Ecuador. Conaie.

Córdova, E. y Vargas, H. (2003). Bolivia: un país de re-configuraciones por una cultura de pactos políticos y de conflictos. En J. Seoane (Comp.), Movimientos sociales y conflictos en América Latina (pp. 39-47). . Consejo Latinoamericano de Ciencias Sociales (Clacso).

Campos en Ciencias Sociales

ISSN: 2339-3688 | e-ISSN: 2500-6681 | DOI: https://doi.org/10.15332/25394363

Vol. 9 N. ${ }^{\circ} 1$ | enero-junio de 2021 
Cuba, L. (2006). Bolivia: movimientos sociales, nacionalización y asamblea constituyente., Observatorio Social de América Latina, (19).

Chávez, P. y Mokrani, D. (2007). Los Movimientos Sociales en la Asamblea Constituyente. Hacia la reconfiguración de la política. Observatorio Social de América Latina, (22).

Dávalos, P. (2006). Movimientos sociales y razón liberal: los límites de la historia.

Observatorio Social de América Latina, 7(20). http://biblioteca.clacso.edu.ar/ar/libros/osal/osal20/davalos.pdf

Díez, A. y García Yapur, F. (2007a). Estado Plurinacional. Cervantes.

Díez, A. y García Yapur, F. (2007b). La Interculturalidad en el proceso constituyente. Cervantes.

García, A. (2007). El desencuentro de dos razones revolucionarias Indianismo y Marxismo. Consejo Latinoamericano de Ciencias Sociales (Clacso).

García, A. (2006). Democracia liberal vs. democracia comunitaria. En W. Mignolo (Comp.), Interculturalidad, descolonización del estado y del conocimiento. Ediciones del Signo.

Gómez, M., Idrobo-Velasco, J. A., Rincón, C. y Restrepo, A. (2020). Ideología y latifundio en América Latina. Utopía y Praxis Latinoamericana, (25), 77-95. https://produccioncientificaluz.org/index.php/utopia/article/view/34503

Grupo Latinoamericano de Estudios Subalternos. (1998). Manifiesto inaugural. En E. Mendieta y S. Castro Gómez (Comps.), Teorías sin disciplina (latinoamericanismo, poscolonialidad y globalización en debate). Librería Porrúa.

Idrobo, J. (2012). Awayu: el tejido de la identidad diversa latinoamericana. Constitución ontológica de una tradición ancestral como posibilidad de interpretación. En Cáceres, I. y Quesada, A. (Eds.), Identidad... ¿Latinoamericana? Diálogos de multiplicidades (pp. 59-70). Academia Libre y Popular Latinoamericana de Humanidades. 59-70.

Idrobo, J. y Orrego, I. (2020). Territorios, conflictos y resistencias. Ediciones USTA.

Linera, Á. (2007). El desencuentro de dos razones revolucionarias Indianismo y Marxismo. Observatorio Social de América Latina, (3), 477-500. http://bibliotecavirtual.clacso.org.ar/ar/libros/coedicion/linera/7.3.pdf

Campos en Ciencias Sociales ISSN: 2339-3688 | e-ISSN: 2500-6681 | DOI: https://doi.org/10.15332/25394363 
Linera, Á. (2006). Democracia liberal vs democracia comunitaria. En W. Mignolo (Comp.), Interculturalidad, descolonización del estado y del conocimiento (pp. 71-82). Ediciones del Signo.

Mignolo, W. (2006). Interculturalidad, descolonización del estado y del conocimiento. Ediciones del Signo.

Mignolo, W. (2005). La idea de América Latina, la herida colonial y la opción decolonial. Editorial Gedisa.

Orellana, L. (2005). Hacia una caracterización del gobierno de Evo Morales. Observatorio Social de América Latina, (19), 45-54. http://bibliotecavirtual.clacso.org.ar/ar/libros/osal/osal19/aillon.pdf

Organizaciones Indígenas, Originarias, Campesinas y de Colonizadores hacia la Asamblea Constituyente. (2006). Propuesta para la nueva constitución política del estado "por un estado plurinacional y la autodeterminación de los pueblos y naciones indígenas, originarias y campesinas".

http://www.constituyentesoberana.org/3/propuestas/osio/Pactodeunidad.pdf

Organizaciones Sociales Bolivianas. (2006). Manifiesto de la Asamblea Nacional de Organizaciones Indígenas, Originarias, Campesinas y de Colonizadores de Bolivia. http://www.aporrea.org/internacionales/a24397.html

Puente, F. y Longa, F. (2007). El alto: los dilemas del indigenismo urbano entre la insurrección y el clientelismo. En M. Svampa y P. Stefanoni (Comps.), Bolivia: memoria, insurgencia y movimientos sociales (pp. 97-123). Editorial El Colectivo.

Walsh, C. (2009). Interculturalidad, Estado y sociedad. Luchas (de) coloniales de nuestra época. Universidad Andina Simón Bolívar-Ecuador; Editorial Abya Yala.

Walsh, C. (2006). Interculturalidad y Colonialidad del Poder. Un pensamiento y posicionamiento otro desde la diferencia cultural. En W. Mignolo (Comp.), Interculturalidad, descolonización del estado y del conocimiento (pp. 21-70). Ediciones del Signo.

Zibechi, R, (2006). Movimientos sociales: nuevos escenarios y desafíos inéditos. Observatorio Social de América Latina, (21). http://biblioteca.clacso.edu.ar/clacso/osal/20110411090916/10Zibechi.pdf 